\title{
Communications: Elementary oxygen electrode reactions in the aprotic Li-air battery
}

Hummelshøj, Jens Strabo; Blomquist, Jakob; Datta, Soumendu; Vegge, Tejs; Rossmeisl, Jan; Thygesen, Kristian Sommer; Luntz, A. C.; Jacobsen, Karsten Wedel; Nørskov, Jens Kehlet

Published in:

Journal of Chemical Physics

Link to article, DOI:

$10.1063 / 1.3298994$

Publication date:

2010

Document Version

Publisher's PDF, also known as Version of record

Link back to DTU Orbit

Citation $(A P A)$ :

Hummelshøj, J. S., Blomquist, J., Datta, S., Vegge, T., Rossmeisl, J., Thygesen, K. S., Luntz, A. C., Jacobsen, K. W., \& Nørskov, J. K. (2010). Communications: Elementary oxygen electrode reactions in the aprotic Li-air battery. Journal of Chemical Physics, 132(7), 071101. https://doi.org/10.1063/1.3298994

\section{General rights}

Copyright and moral rights for the publications made accessible in the public portal are retained by the authors and/or other copyright owners and it is a condition of accessing publications that users recognise and abide by the legal requirements associated with these rights.

- Users may download and print one copy of any publication from the public portal for the purpose of private study or research.

- You may not further distribute the material or use it for any profit-making activity or commercial gain

- You may freely distribute the URL identifying the publication in the public portal 


\title{
Communications: Elementary oxygen electrode reactions in the aprotic Li-air battery
}

\author{
J. S. Hummelshøj, ${ }^{1}$ J. Blomqvist, ${ }^{1}$ S. Datta, ${ }^{1}$ T. Vegge, ${ }^{2}$ J. Rossmeisl, ${ }^{1}$ K. S. Thygesen, ${ }^{1}$ \\ A. C. Luntz, ${ }^{3}$ K. W. Jacobsen, ${ }^{1}$ and J. K. Nørskov ${ }^{\uparrow}$ \\ ${ }^{1}$ Department of Physics, Center for Atomic-scale Materials Design, Technical University of Denmark, \\ DK-2800 Lyngby, Denmark \\ ${ }^{2}$ Materials Research Division, Ris $\phi$ National Laboratory for Sustainable Energy, \\ Technical University of Denmark, DK-2800 Lyngby, Denmark \\ ${ }^{3}$ Institute of Physics and Chemistry, University of Southern Denmark, DK-5230 Odense, Denmark; \\ IBM Almaden Research, San Jose, California 95120, USA
}

(Received 1 October 2009; accepted 4 January 2010; published online 16 February 2010)

\begin{abstract}
We discuss the electrochemical reactions at the oxygen electrode of an aprotic Li-air battery. Using density functional theory to estimate the free energy of intermediates during the discharge and charge of the battery, we introduce a reaction free energy diagram and identify possible origins of the overpotential for both processes. We also address the question of electron conductivity through the $\mathrm{Li}_{2} \mathrm{O}_{2}$ electrode and show that in the presence of $\mathrm{Li}$ vacancies $\mathrm{Li}_{2} \mathrm{O}_{2}$ becomes a conductor. (C) 2010 American Institute of Physics. [doi:10.1063/1.3298994]
\end{abstract}

There is a general recognition that a staged and gradual transition from pure internal combustion engine driven vehicles to electric vehicles (EVs) is attractive for light vehicle transportation in order to minimize dependence on oil products and combat global $\mathrm{CO}_{2}$ emissions. At present, the fundamental limitation in the implementation of this strategy is the limited range of EVs due to the limited gravimetric and volumetric electrical energy storage densities in existing batteries. While future advanced Li-ion batteries can possibly extend the range slightly, there is little hope that even the gravimetric densities of these future batteries will be sufficient to allow ranges for a majority of current daily driving habits. Several possible alternative battery chemistries, e.g., metal-air batteries, could, in principle, provide significantly higher electrical storage densities. Of these, the aprotic Li-air battery is the most attractive since it potentially could provide the highest energy storage density $(\sim 1600 \mathrm{~W} \mathrm{~h} / \mathrm{kg})$ and has been demonstrated to be rechargeable. ${ }^{1-3}$ However, there are, many technical problems confronting the development of a practical Li-air battery. One of the more fundamental ones is the limited power density and electrical efficiency obtainable from such a battery due to the strong polarization losses at the cathode, both in discharge ${ }^{4}$ and in charge. ${ }^{1-3}$ Therefore, understanding the mechanism of the electrochemical reactions and the origin of the overpotentials is a key first step in developing practical Li-air batteries.

In the present letter, we concentrate on the oxygen electrode and introduce a simple picture to understand the potential dependence of the processes taking place at the electrode surface. We use density functional theory (DFT) calculations to provide an estimate of the energy of important intermediates in the process and discuss on this basis the origin of the overpotential for the discharge reactions as well as the origin of the asymmetry in overpotential between discharge and

${ }^{a)}$ Electronic mail: norskov@fysik.dtu.dk. recharge. Finally, we address the question whether the electron transport through $\mathrm{Li}_{2} \mathrm{O}_{2}$ might be rate limiting.

In the Li-air battery, the net reaction during discharge is the oxidation of metallic lithium to form lithium peroxide,

$$
2 \mathrm{Li}+\mathrm{O}_{2} \rightarrow \mathrm{Li}_{2} \mathrm{O}_{2} .
$$

Before suggesting a possible mechanism for the electrochemistry, we first note a few experimental facts: ${ }^{1-3}$ (1) The product of the discharge reaction, $\mathrm{Li}_{2} \mathrm{O}_{2}$, is extremely insoluble in the typical aprotic solvents used, e.g., propylene carbonate; (2) after a very brief initial transient, both the discharge and charge voltages (for a given current) remain essentially constant throughout the discharge/charge process until the process terminates; (3) at the end of the discharge process, close packed mesoscale balls $(\sim 200 \mathrm{~nm})$ of $\mathrm{Li}_{2} \mathrm{O}_{2}$ are formed on the $\mathrm{C}$ electrode. Combined together, these facts suggest that the electrochemistry being observed during discharge is that of $\mathrm{Li}_{2} \mathrm{O}_{2}$ formation on the surface of $\mathrm{Li}_{2} \mathrm{O}_{2}$ (and vice versa for charge). On this basis, we investigate a mechanism involving the following steps in the electrochemical oxidation of bulk metallic Li:

$$
\begin{aligned}
& \mathrm{Li} \rightarrow \mathrm{Li}^{+}+\mathrm{e}^{-} \quad(\mathrm{Li} \text { electrode }) \\
& \mathrm{Li}^{+}+\mathrm{e}^{-}+\mathrm{O}_{2}+* \rightarrow \mathrm{LiO}_{2}^{*} \quad\left(\mathrm{O}_{2} \text { electrode step } 1\right), \\
& \mathrm{Li}^{+}+\mathrm{e}^{-}+\mathrm{LiO}_{2}^{*} \rightarrow \mathrm{Li}_{2} \mathrm{O}_{2} \quad\left(\mathrm{O}_{2} \text { electrode step } 2\right) .
\end{aligned}
$$

Here, the first step, the dissolution of metallic $\mathrm{Li}$ into the electrolyte, is assumed to be in equilibrium. The free energy of $\mathrm{Li}^{+}+\mathrm{e}^{-}$at potential $\mathrm{U}=0$ is defined to be zero and equal to that of bulk Li. At a finite potential the free energy of the electron on the right side of the reaction is shifted by $-\mathrm{eU}$. At the oxygen electrode, we will consider the electrochemical growth of $\mathrm{Li}_{2} \mathrm{O}_{2}$. This will describe all the oxygen electrode processes except the initial nucleation of $\mathrm{Li}_{2} \mathrm{O}_{2}$ on the carbon support. * denotes a surface site on $\mathrm{Li}_{2} \mathrm{O}_{2}$ where the 
a)

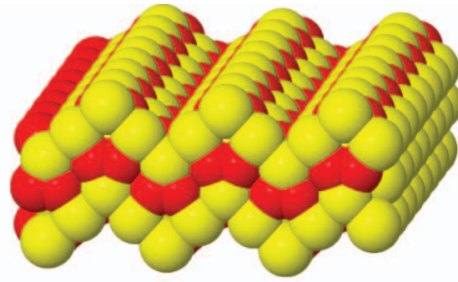

c)

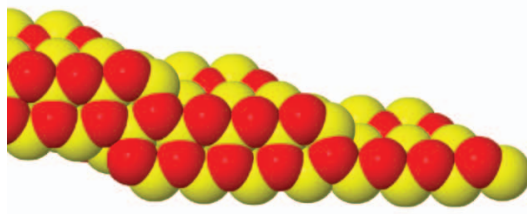

f)

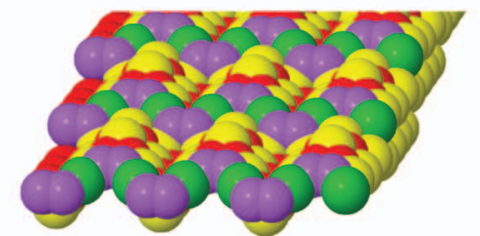

d)

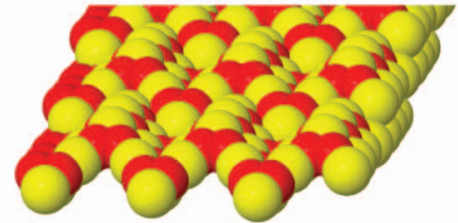

g)

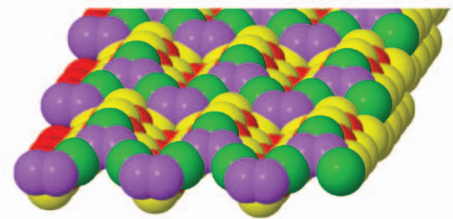

b)

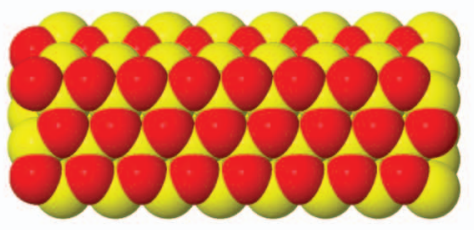

e)

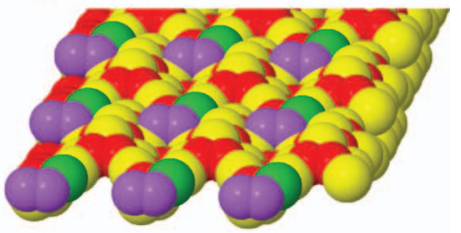

h)

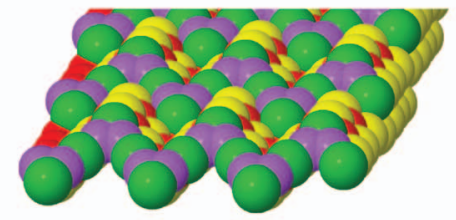

FIG. 1. Structure of the $\mathrm{Li}_{2} \mathrm{O}_{2}(100)$ surface, where the yellow is $\mathrm{Li}$ and the red oxygen. The lowest energy reconstructed surface is shown in perspective in (a) and from the side in (b). The stepped surface used in the calculations is shown from the side in (c) while (d)-(h) show the structure of intermediates during discharge; the green atoms are the $\mathrm{Li}$ and the purple are the oxygen that have been added since (d). The corresponding energies are shown in Fig. 2. (h) is the same as (d) except that the step has shifted by two formula units. The net result is that two bulk two formula units of $\mathrm{Li}_{2} \mathrm{O}_{2}$ have been added to the system. The surface area and step length is preserved.

growth proceeds. We will assume that electrons can be transferred to the surface of $\mathrm{Li}_{2} \mathrm{O}_{2}$; and this will be discussed further below. We consider in the following the growth of the (100) surface. We have studied several low index surfaces, and they all behave similarly. We chose to study the (100) surface in detail since it is the most stable surface we found, and it is therefore expected to be the most abundant surface on the $\mathrm{Li}_{2} \mathrm{O}_{2}$ particles formed during discharge.

The DFT calculations are performed using the real space grid-based code GPAW, ${ }^{5}$ which is based on the projectoraugmented wave method. ${ }^{6}$ All calculations are spin polarized and performed using the RPBE exchange correlation functional. ${ }^{7}$ Typical super cell slabs contain 64 atoms separated by $\sim 18 \AA$ vacuum layers (Fig. 1) and are sampled with a $(2,2,1)$ k-point grid and a grid spacing of $0.15 \AA$. Given the poor DFT description of the triplet ground state of $\mathrm{O}_{2}$, we use the more accurate values for $\mathrm{H}_{2} \mathrm{O}$ and $\mathrm{H}_{2}$ as a reference together with the experimental formation energy for water (corrected for zero-point energies), ${ }^{8}$ i.e., $\mathrm{E}\left(\mathrm{O}_{2}\right)$ $=2 \mathrm{E}_{\mathrm{GPAW}}\left(\mathrm{H}_{2} \mathrm{O}\right)-2 \mathrm{E}_{\mathrm{GPAW}}\left(\mathrm{H}_{2}\right)-2 \Delta \mathrm{E}_{\text {expt }}\left(\mathrm{H}_{2} \mathrm{O}\right)$.

Free energies are estimated by including the entropy of gas phase $\mathrm{O}_{2}[-\mathrm{T} \Delta \mathrm{S}=-0.63 \mathrm{eV}$ at standard conditions, 1 bar and $298 \mathrm{~K}$ (Ref. 9)] exploiting that the entropy of the solid phases is small. The quality of the calculations can be gauged by the fact that we find a heat of formation of $\mathrm{Li}_{2} \mathrm{O}_{2}$ of $\Delta \mathrm{H}=-5.57 \mathrm{eV}$ (free energy of formation of $\Delta \mathrm{G}=$ $-4.94 \mathrm{eV}$ ) as compared to experimental values of $\Delta \mathrm{H}=$ $-6.56 \mathrm{eV}$ and $\Delta \mathrm{G}=-5.91 \mathrm{eV}$, respectively. ${ }^{10}$ This means that we have an equilibrium potential $\mathrm{U}_{0}=-\Delta \mathrm{G} / 2 \mathrm{e}$ $=2.47 \mathrm{~V}$ rather than the experimental value of $2.96 \mathrm{~V}$. While the agreement between theory and experiment is not perfect it is good enough that the picture developed in the following is expected to be qualitatively correct.
The lowest energy structure of the $\mathrm{Li}_{2} \mathrm{O}_{2}(100)$ surface is shown in Fig. 1(a). We find that this surface is most stable in a missing row reconstruction. In general, the growth of a surface is most simply described as deposition of material at kinks. When one surface unit cell of material is deposited at the kink, the surface is indistinguishable from the starting point except that the kink has moved and one unit cell of bulk material has been added. For the $\mathrm{Li}_{2} \mathrm{O}_{2}(100)$ surface, the reconstruction discussed above has two important consequences. First, the missing rows essentially decouple the rows of $\mathrm{Li}_{2} \mathrm{O}_{2}$ so that they will grow independently. That means that we can consider a stepped surface rather than a kinked surface. The stepped surface shown in Figs. 1(c)-1(h) is simpler to treat computationally, and because of the large distance to the next row of $\mathrm{Li}_{2} \mathrm{O}_{2}$, the coupling between rows is small and adding or removing material to this structure is essentially the same as at a kinked surface. Second, since the surface unit cell contains two formula units of $\mathrm{Li}_{2} \mathrm{O}_{2}$ reaction steps 1 and 2 above need to run twice before the initial and final states of the surface are the same.

Figure 2 shows the calculated free energy diagram at different potentials. We show step 1 twice (but with different reaction free energies since the two $\mathrm{LiO}_{2}^{*}$ that are added are not equivalent) followed by step 2 twice (again with different reaction free energies) since that gives smallest free energy variations at the high potentials where processes run. The effect of a finite potential $U$ is included by adding an energy, - neU, to the calculated free energy for every intermediate with $\mathrm{n}$ electrons in the electrode. ${ }^{8}$ Effects of the solvent or electrical fields at the surface have not been included here. Experience from similar calculations at the solid-water interface suggests that such effects are quite small and are mainly present in cases where there is substantial hydrogen 


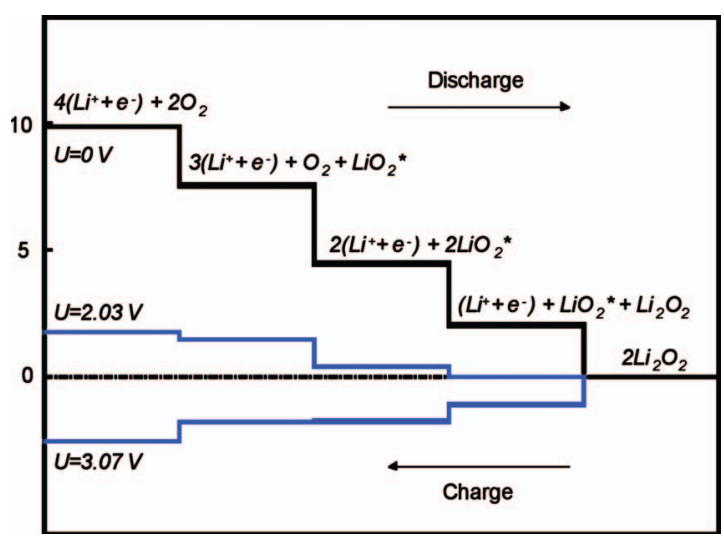

FIG. 2. Calculated free energy diagram for the reactions at the oxygen electrode of a Li-air battery. Two formula units are added during discharge (left to right) or removed during charge (right to left). The free energies are shown at different potentials, $\mathrm{U}=0$ is the open circuit potential, $\mathrm{U}$ $=2.03 \mathrm{~V}$ is the highest potential where discharge is still downhill in all steps, and $\mathrm{U}=3.07 \mathrm{~V}$ is the lowest potential where charging is all downhill.

bonding, ${ }^{11}$ but this is clearly an area where more detailed calculations would be of interest.

All reaction steps in Fig. 2 are simple adsorption and desorption processes. There may be additional energy barriers associated with, e.g., the loss of solvation of $\mathrm{Li}^{+}$in the electrolyte during adsorption, but we expect the free energies of adsorption to represent the potential-dependent part of the adsorption barriers. The free energy diagram can therefore be used to get an idea of the potential dependence of the process. First, consider the discharge reaction (from left to right in Fig. 2). At zero potential, all reaction steps are downhill and the electrode reaction should be facile. As the potential is increased, all steps remain downhill until a potential of $\mathrm{U}_{\text {discharge }}=\min \left[-\Delta \mathrm{G}_{\mathrm{i}} / \mathrm{e}\right]=2.03 \mathrm{~V}$ is reached. At higher potentials, the two $\mathrm{Li}^{+}+\mathrm{e}^{-}$transfers are uphill in free energy. We suggest that this is the origin of the slow kinetics of the discharge reaction close to the equilibrium potential. We identify $\eta_{\text {discharge }}=\mathrm{U}_{0}-\mathrm{U}_{\text {discharge }}=0.43 \mathrm{~V}$ as a (theoretical) measure of the overpotential for the discharge reaction. This value is quite consistent with the experimental observations that typically, discharge takes place about $0.3 \mathrm{~V}$ below the equilibrium potential. It should be stressed that the current density depends exponentially on $\eta_{\text {discharge }}$. This means that as long as the electrode processes are rate determining, the working potential will depend roughly logarithmically on the current density and this has been observed experimentally. ${ }^{4}$

We now turn to the charging process. As shown in Fig. 2, the process running from right to left will be all downhill at a potential of $3.07 \mathrm{~V}$ or above. Now, it is the electron transfer step resulting in the first release of $\mathrm{O}_{2}$ and $\mathrm{Li}^{+}$which is rate limiting; $\mathrm{U}_{\text {charge }}=\max \left[-\Delta \mathrm{G}_{\mathrm{i}} / \mathrm{e}\right]=3.07 \mathrm{~V}$. The theoretical overpotential then becomes $\eta_{\text {charge }}=\mathrm{U}_{\text {charge }}-\mathrm{U}_{0}=0.60 \mathrm{~V}$, somewhat larger than $\eta_{\text {discharge }}$. This is in qualitative agreement with the experimental observations that the charging always takes place at a larger potential relative to the equilibrium potential than discharge. It is interesting to note that the asymmetry between discharge and charging in our model is a direct consequence of the fact that a turnover of two formula units is needed to complete the catalytic cycle of

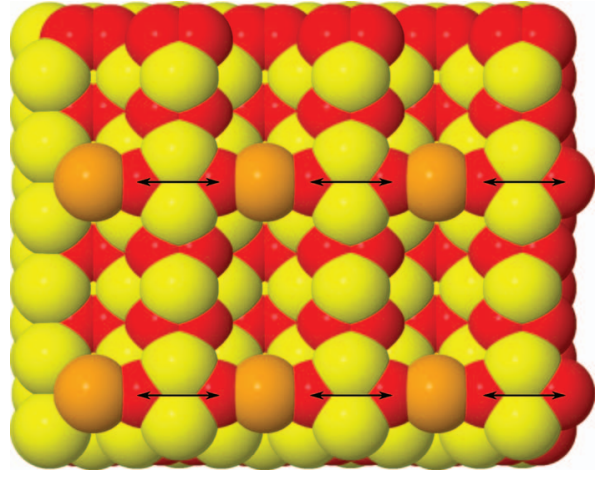

FIG. 3. Dissociation of $\mathrm{O}_{2}$ to form $\mathrm{Li}_{2} \mathrm{O}$ at the surface of $\mathrm{Li}_{2} \mathrm{O}_{2}$ with excess Li. The extra $\mathrm{Li}$ is shown as orange and the $\mathrm{O}_{2}$ bond that is broken subsequent to adding the $\mathrm{Li}$ is indicated by the double arrow.

$\mathrm{Li}_{2} \mathrm{O}_{2}$ growth or dissolution. This effectively makes it a four electron process. If only one formula unit was needed (a two-electron process), one intermediate would be sufficient and there would always be symmetry between discharge and charge overpotentials.

The asymmetry that we find between charge and discharge is smaller than the one found experimentally. This may be due to errors in the DFT calculations, but it may also mean that there are additional factors affecting the charging and discharging potential. Each of the reaction steps considered might consist of several elementary processes and if one of these is nonelectrochemical, new interesting possibilities will appear. Imagine that reaction step (1) $\mathrm{Li}^{+}+\mathrm{e}^{-}+\mathrm{O}_{2}+* \rightarrow \mathrm{LiO}_{2}^{*}$ in fact consists of two steps-(1a) $\mathrm{O}_{2}+* \rightarrow \mathrm{O}_{2}^{*}$ and (1b) $\mathrm{Li}^{+}+\mathrm{e}^{-}+\mathrm{O}_{2}^{*} \rightarrow \mathrm{LiO}_{2}^{*}$-so that only the second step involves a charge transfer. If (1a) is downhill in free energy by $\Delta \mathrm{G}_{1 \mathrm{a}}$ the maximum discharge potential is reduced by $-\Delta \mathrm{G}_{1 \mathrm{a}}$, but the rate of discharge will not be affected. The charging reaction, on the other hand, will be slowed down by a factor $\sim \exp \left(\Delta \mathrm{G}_{1 \mathrm{a}} / \mathrm{kT}\right)$. This could add considerably to the asymmetry. We note that if $\mathrm{O}_{2}$ desorption is made more facile by $\mathrm{O}_{2}$ moving to the surface of another solid, e.g., $\mathrm{MnO}_{2}$, that would alleviate the problems with this nonpotential dependent step. This may be the origin of the catalytic effect observed in charging. ${ }^{12}$

Due to charge transfer and the asymmetric positions of the atoms in the intermediate states, local dipole moments are present, and one could imagine that the electric fields present during charge and discharge could affect the energies. However, our calculations show that an electric field of $\sim 0.4 \mathrm{~V} / \AA$ 路ly change the relative energies by $\sim 0.1 \mathrm{eV}$.

The calculations also revealed a competing process which could make the coulombic efficiency for discharge and recharge $\ll 1$. If there is a surplus of $\mathrm{Li}$ on the surface for any reason, then $\mathrm{O}_{2}$ dissociates spontaneously, and $\mathrm{Li}_{2} \mathrm{O}$ is formed locally, see Fig. 3. During discharge, this could happen if the system is starved in $\mathrm{O}_{2}$, and there is experimental evidence for that. ${ }^{3}$ During recharge, where the potential of the oxygen electrode is very high (electrons are removed from the electrode) $\mathrm{O}_{2}^{-}$is destabilized and oxygen desorption may become possible. Forming $\mathrm{Li}_{2} \mathrm{O}$ is another way of inhibiting recharge, and if this is a significant mechanism of decay of $\mathrm{Li}_{2} \mathrm{O}_{2}$, it could limit cycleability of the battery. 


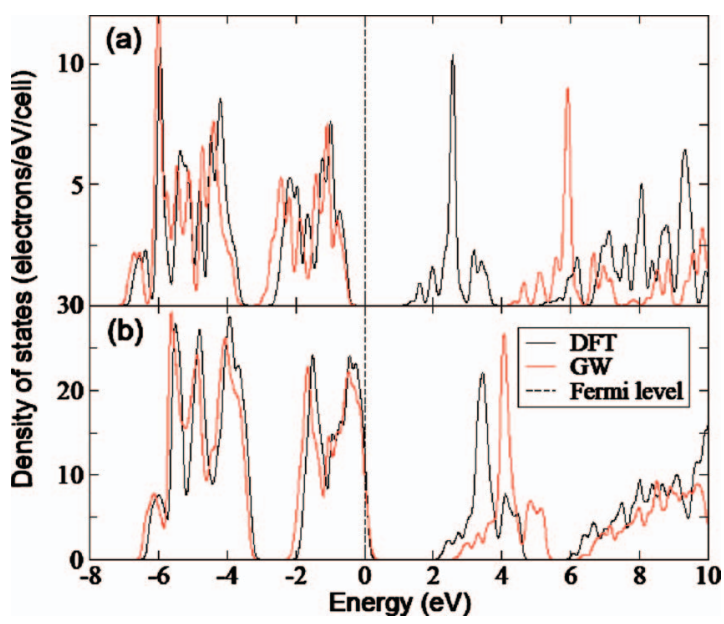

FIG. 4. Calculated density of states for (a) pure $\mathrm{Li}_{2} \mathrm{O}_{2}$ and (b) $\mathrm{Li}_{2} \mathrm{O}_{2}$ with a concentration of $1 / 16 \mathrm{Li}$ vacancies. The black curve shows the DFT singleparticle spectrum and the red curve shows the GW quasiparticle spectrum. In (a), the top of the valence bands have been aligned and in (b) the Fermi levels have been aligned.

Finally, we address the question whether electron transfer through $\mathrm{Li}_{2} \mathrm{O}_{2}$ could be rate limiting. $\mathrm{Li}_{2} \mathrm{O}_{2}$ is an insulator and one could wonder how electrons are transferred to and from the active surface. A DFT calculation of the oneelectron spectrum shows $\mathrm{Li}_{2} \mathrm{O}_{2}$ to have a considerable band gap, see Fig. 4(a). A more accurate $\mathrm{G}_{0} \mathrm{~W}_{0}$ calculation of the real quasiparticle spectrum gives the same qualitative result, although with a larger band gap (4.91 eV as opposed to 1.88 $\mathrm{eV}$ in the DFT calculations). The $\mathrm{G}_{0} \mathrm{~W}_{0}$ calculations have been performed with the YAMBO code ${ }^{13}$ using a $30 \mathrm{eV}$ cutoff for the sum over virtual states, and a $(6,6,2) \mathrm{k}$-point mesh (eight atoms per unit cell). The electronic wave functions used as input to the $\mathrm{G}_{0} \mathrm{~W}_{0}$ calculations have been obtained with the PWSCF code ${ }^{14}$ using norm-conserving pseudopotentials, a 100 Ry cutoff for the plane wave expansion, and the PBE exchange-correlation functional.

If we perform similar calculations for $\mathrm{Li}_{2} \mathrm{O}_{2}$ with $\mathrm{Li}$ vacancies, the picture changes, as shown in Fig. 4(b). Now, holes are created in the valence band and the system becomes an electronic conductor. The bulk vacancy formation energy is calculated to be $2.85 \mathrm{eV}$ (quite independent of the vacancy density). We also note that the $\mathrm{Li}$ vacancies are quite mobile in the solid. The activation energy for vacancy diffusion is calculated to be $0.35 \mathrm{eV}$ along the 100 planes. This means that from a thermodynamic point of view bulk $\mathrm{Li}$ vacancies can be created at a potential of $2.85 \mathrm{~V}$. Thus, certainly during recharge there is always a thermodynamic driving force for Li vacancy formation. During discharge, there may not be many bulk Li vacancies, but there will always be a high concentration of Li vacancies at the surface. The rea- son is that they are intermediates in the process and discharge cannot proceed without vacancies being present. Surface vacancies will introduce holes in the valance band just as bulk vacancies, and we therefore conclude that there will always be metallic states present in or on the surface of $\mathrm{Li}_{2} \mathrm{O}_{2}$ during the operation of the Li-air battery. The question remains whether surface conductivity is enough to maintain high current densities during discharge.

We have presented a very simple model of the processes at the oxygen electrode of an aprotic Li-air battery. Using DFT calculations to estimate the energy of the intermediates of the reactions, we have established an understanding of important contributions to the overpotential for both discharge and recharge of the battery. In addition, we have shown that the issue of electron transport through the $\mathrm{Li}_{2} \mathrm{O}_{2}$ may not be a problem at the high potentials found during operation of the battery. We consider the analysis given above to be the simplest possible and is a first attempt at understanding the origin of the overpotentials for charging and recharging of the Li-air battery. More complicated reaction paths, e.g., involving bond breaking of $\mathrm{O}_{2}$ and local formation of $\mathrm{Li}_{2} \mathrm{O}$ should be investigated further, as well as the effect of impurities and adsorbed species from the electrolyte.

${ }^{1}$ K. M. Abraham and Z. J. Jiang, J. Electrochem. Soc. 143, 1 (1996).

${ }^{2}$ T. Ogasawara, A. Debart, M. Holzapfel, P. Novak, and P. G. Bruce, J. Am. Chem. Soc. 128, 1390 (2006).

${ }^{3}$ J. Read, J. Electrochem. Soc. 149, A1190 (2002).

${ }^{4}$ X.-H. Yang, and Y.-Y. Xia, J. Solid State Electrochem. 14, 109 (2010).

${ }^{5}$ J. J. Mortensen, L. B. Hansen, and K. W. Jacobsen, Phys. Rev. B 71, 035109 (2005); the GPAW code is available as a part of the CAMPOS software, www.camd.dtu.dk/Software.

${ }^{6}$ P. E. Blöchl, Phys. Rev. B 50, 17953 (1994); P. E. Blöchl, C. J. Först, and J. Schimpl, Bull. Mater. Sci. 26, 33 (2003).

${ }^{7}$ B. Hammer, L. B. Hansen, and J. K. Nørskov, Phys. Rev. B 59, 7413 (1999).

${ }^{8}$ J. K. Nørskov, J. Rossmeisl, A. Logadottir, L. Lindqvist, J. R. Kitchin, T. Bligaard, and H. Jonsson, J. Phys. Chem. B 108, 17886 (2004).

${ }^{9}$ P. Atkins and J. dePaula, Physical Chemistry, 7th ed. (Oxford University Press, Oxford, 2002).

${ }^{10}$ M. W. Chase, Jr., J. Phys. Chem. Ref. Data Monogr. 9, 1 (1998).

${ }^{11}$ J. Rossmeisl, J. K. Nørskov, C. D. Taylor, M. J. Janik, and M. Neurock, J. Phys. Chem. B 110, 21833 (2006); G. S. Karlberg, J. Rossmeisl, and J. K. Nørskov, Phys. Chem. Chem. Phys. 9, 5158 (2007).

${ }^{12}$ A. Débart, J. Bao, G. Armstrong, and P. G. Bruce, J. Power Sources 174, 1177 (2007).

${ }^{13}$ A. Marini, C. Hogan, M. Gruening, and D. Varsano, Comput. Phys. Commun. 180, 1392 (2009).

${ }^{14}$ P. Giannozzi, S. Baroni, N. Bonini, M. Calandra, R. Car, C. Cavazzoni, D. Ceresoli, G. L. Chiarotti, M. Cococcioni, I. Dabo, A. Dal Corso, S. Fabris, G. Fratesi, S. de Gironcoli, R. Gebauer, U. Gerstmann, C. Gougoussis, A. Kokalj, M. Lazzeri, L. Martin-Samos, N. Marzari, F. Mauri, R. Mazzarello, S. Paolini, A. Pasquarello, L. Paulatto, C. Sbraccia, S. Scandolo, G. Sclauzero, A. P. Seitsonen, A. Smogunov, P. Umari, and R. M. Wentzcovitch, J. Phys.: Condens. Matter 21, 395502 (2009). 